\title{
A Multi-Attribute Decision Making for Investment Decision Based on D Numbers Methods
}

\author{
Qian Zuo, Xuanhua Qin, Youzhen Tian, Daijun Wei \\ School of Science, Hubei University for Nationalities, Enshi, China \\ Email: prof.wei@hotmail.com, 2001013@hbmy.edu.cn
}

How to cite this paper: Zuo, Q., Qin, X.H., Tian, Y.Z. and Wei, D.J. (2016) A Multi-Attribute Decision Making for Investment Decision Based on D Numbers Methods. Advances in Pure Mathematics, 6, 765-775.

http://dx.doi.org/10.4236/apm.2016.612062

Received: October 7, 2016

Accepted: November 5, 2016

Published: November 8, 2016

Copyright $\odot 2016$ by authors and Scientific Research Publishing Inc. This work is licensed under the Creative Commons Attribution International License (CC BY 4.0).

http://creativecommons.org/licenses/by/4.0/

\begin{abstract}
Investment decision is a traditional multi-attribute decision making (MADM) problem since it has many uncertainty factors and incomplete information such as investment value, cost, sales, etc. D numbers theory is a useful tool to deal with uncertainty factors and incomplete information. In this paper, interval number and D numbers theory are revealed in the uncertain factor and incomplete information of investment decision. The weights of uncertain factors are calculated using entropy weight method. Thus, a new MADM model for investment decision based on $\mathrm{D}$ numbers theory is proposed. Numerical example is used to illustrate the efficiency of the proposed method.
\end{abstract}

\section{Keywords}

Uncertainty, MADM, Investment Decision, D Numbers, Entropy Weight

\section{(c) (i) Open Access}

\section{Introduction}

The aim of investment decision is to make maximize gains and minimize risk under uncertain environment. Variance portfolio model was a powerful tool to handle investment decision and established by Markowitzin in 1952 [1] [2], which marked the beginning of the model securities portfolio investment theory. This model, Markowitz's Portfolio theory [3] [4] [5] [6], was modified by Sharpes Capital Asset Pricing model [7] [8] and Rosss Arbitrage Pricing theory [9] [10] [11], then it was used to solve the investment decision making problem. In these methods, the factor of investment decision is usually represented by real numbers. However, indeed, the investment decision making is relative to many criteria, which are uncertainty. Investment decision making can be seen as a MADM problem. MADM has been studied by many researchers [12] [13] [14] [15] [16]. For MADM, two problems are key issues. One is that how to 
represent uncertain factors and another is how to fuse these uncertain factors. Many methods are applied to reveal uncertainty factors such as fuzzy set method [17], rough set method [18], probability method [19] [20] and interval numbers [21] [22]. The interval number is an effective way to solve the problem of uncertainty since its value range is bigger than real number, and that has simple forms. Thus, the interval numbers represented kinds of uncertain factors for investment decision making [23] [24]. For the second problem, Dempster-Shafer (D-S) theory was a useful tool to handle it. D-S theory was first proposed by Dempster in 1967, which was further developed by Shafer in 1976. The basic probability assignment (BPA) in Dempster-Shafer (D-S) theory represents the information of both certain or uncertain. Furthermore, the Depmster's combination rule can combine multiple BPAs. Thus, Dempster-Shafer theory of evidence has been widely used in multiple criteria decision making [25]-[30]. However, D-S theory has some drawback, such as the completeness constraint and exclusiveness hypothesis [31]. As improved D-S theory, D numbers theory is proposed in references [31] [32]. D numbers theory removes some strong hypotheses from Dempster-Shafer theory of evidence. It enables the D numbers theory more powerful in dealing with uncertainty as well as incompleteness. In D numbers theory, the elements may be compatible. Meanwhile, framework may be incomplete. D numbers theory is a powerful tool to handle incomplete and uncertainty information. Thus, D numbers theory is applied into many fields, such as environmental impact assessment [33] [34], bridge condition assessment [35] and curtain grouting efficiency assessment [36]. Our goal is to handle investment decision problem using $\mathrm{D}$ numbers method. In this paper, the uncertain information of investment decision is revealed using interval number and D numbers theory. Meanwhile, the weights of uncertain factors are calculated using entropy weight method. Thus, a new MADM model for investment decision is proposed. The paper is organized as follows. The preliminaries of interval number, D numbers theory and entropy weight method are introduced in Section 2. The proposed method and an illustrative example are given in Section 3. Some conclusions are drawn in Section 4.

\section{Preliminaries}

\subsection{Interval Number Method}

Interval number is actual a collection of all real numbers on a closed interval. Interval number represents a kind of uncertainty, and it has a great potential for application in different fields, such as establish fuzzy portfolio model and multi-objective portfolio model [37] [38]. An interval number is denoted as $\tilde{x}$, which is defined as follows [37].

Definition 2.1. If $x^{U}$ is the upper bound of the range, $x^{L}$ is the lower range, we have:

$$
\tilde{x}=\left[x^{L}, x^{U}\right]=\left\{a \mid x^{L} \leq a \leq x^{U}, x^{L}, x^{U} \in R\right\}
$$

Especially, the interval number $\tilde{x}$ is a real number when $x^{L}=x^{U}$.

For two interval numbers, $\tilde{x}=\left[x^{L}, x^{U}\right]$ and $\tilde{y}=\left[y^{L}, y^{U}\right]$, they are some properties as follows, 
1) $\tilde{x}=\tilde{y}$ if $x^{L}=y^{L}$ and $x^{U}=y^{U}$.

2) $\tilde{x}+\tilde{y}=\left[x^{L}+y^{L}, x^{U}+y^{U}\right]$.

3) $\lambda \tilde{x}=\left[\lambda x^{L}, \lambda x^{U}\right]$, and when $\lambda=0, \lambda \tilde{x}=0$.

The interval decision matrix is key factors for investment decision. The interval decision is defined as below.

Definition 2.2. A decision matrix $A=\left(a_{i j}\right)$ is composed of interval number $\left[a^{L}, a^{U}\right]$, where

$$
a_{i j}=\frac{\left(a^{L}+a^{U}\right)}{2}
$$

In investment decision, the attributes can be divided into two types: benefit type and cost type. For example, profit is benefit type, while risk is cost type. To eliminate the influence of different physical dimension for the decision result, the standardized original decision matrix is denoted as $R=\left(r_{i j}\right)$, where $r_{i j}$ is defined as below,

$$
r_{i j}=\frac{a_{i j}}{\max _{i}\left(a_{i j}\right)}, i=[1,2,3, \cdots, n], j \in I_{1}
$$

or

$$
r_{i j}=\frac{\min \left(a_{i j}\right)}{a_{i j}}, i=[1,2,3, \cdots, n], j \in I_{2}
$$

where $I_{1}$ belongs benefit type, while $I_{2}$ belongs cost type.

\subsection{Numbers Theory}

D numbers theory is proposed by Deng [31], which is the development of DempsterShafer theory of evidence. It is brief introduced as follows,

Definition 2.3. Let $\Omega$ be a finite nonempty set, $D$ number is a mapping $D$ : $\Omega \rightarrow[0,1]$, it satisfied with

$$
\sum_{B \subset \Omega} D(B) \leq 1 \text { and } D(\phi)=0
$$

where $\phi$ is an empty set and $B$ is a subset of $\Omega$. From the definition, the elements of $\mathrm{D}$ numbers do not mutually exclusive and the sum of assessment can be less than one.

Definition 2.4. For a discrete set $\Omega=\left(b_{1}, b_{2}, b_{3}, \cdots, b_{n}\right)$, where $b_{i}$ belongs to $N^{+}$ and $b_{i} \neq b_{j}$ if $i \neq j$, for any $v_{i} \geq 0$ and $\sum_{i=1}^{n} v_{i} \leq 1$, a special form of $\mathrm{D}$ numbers can be expressed by:

$$
\begin{gathered}
D\left(b_{1}\right)=v_{1} \\
D\left(b_{2}\right)=v_{2} \\
D\left(b_{3}\right)=v_{3} \\
\vdots \\
D\left(b_{n}\right)=v_{n}
\end{gathered}
$$

or be represented simply as: 


$$
D=\left\{\left(b_{1}, v_{1}\right),\left(b_{2}, v_{2}\right),\left(b_{3}, v_{3}\right), \cdots,\left(b_{n}, v_{n}\right)\right\}
$$

An example is given to describe the D numbers. For MADM, the set of $\left\{a_{1}, a_{2}, a_{3}\right\}$ is a frame of discernment. The assessment score belong the interval $[0,100]$, an expert gives his evaluation in the frame of Dempster-Shafer theory, it is shown as below:

$$
\begin{aligned}
& m\left(a_{2}\right)=0.1 \\
& m\left(a_{3}\right)=0.7 \\
& m\left(a_{1}, a_{2}, a_{3}\right)=0.2
\end{aligned}
$$

where $a_{1}=[1,20], a_{2}=[21,64], a_{3}=[65,100]$. The sum of $m_{i}$ equals to one, i.e., it means that information is complete. However, for another assessment, which is denoted as $\left\{b_{1}, b_{2}, b_{3}\right\}$. Some information is incomplete since an expert has not full realization for this assessment [31]. Thus, the assessment is given as follows by D numbers method:

$$
\begin{aligned}
& D\left(b_{2}\right)=0.1 \\
& D\left(b_{3}\right)=0.6 \\
& D\left(b_{1}, b_{2}, b_{3}\right)=0.2
\end{aligned}
$$

where $b_{1}=[1,25], \quad b_{2}=[20,70], b_{3}=[60,100]$, The set of $\left\{b_{1}, b_{2}, b_{3}\right\}$ are not a frame of discernment actually because the intersection between these elements is not empty. The sum value of $D_{i}$ equals to 0.9 , i.e. the information is incomplete. Some rules of D numbers theory are given as follows [31].

Definition 2.5. For a given D numbers, the overall assessment is defined as:

$$
I(D)=\sum_{i=1}^{n} b_{i} v_{i}
$$

In Dempster-Shafer theory of evidence, two BPAs can be fused into a BPA. Similarity, in D numbers method, the fusing rules of two D numbers have been proposed [31]. It is defined as below,

Definition 2.6. Let $D_{1}$ and $D_{2}$ be two $D$ numbers,

$$
\begin{aligned}
& D_{1}=\left\{\left(b_{1}^{1}, v_{1}^{1}\right),\left(b_{2}^{1}, v_{2}^{1}\right),\left(b_{3}^{1}, v_{3}^{1}\right), \cdots,\left(b_{n}^{1}, v_{n}^{1}\right)\right\} \\
& D_{2}=\left\{\left(b_{1}^{2}, v_{1}^{2}\right),\left(b_{2}^{2}, v_{2}^{2}\right),\left(b_{3}^{2}, v_{3}^{2}\right), \cdots,\left(b_{n}^{2}, v_{n}^{2}\right)\right\}
\end{aligned}
$$

The combination of $D_{1}$ and $D_{2}$ denoted by $D=D_{1} \oplus D_{2}$, we have:

$$
D(b)=v
$$

with

$$
\begin{aligned}
& b=\frac{\left(b_{i}^{1}+b_{j}^{1}\right)}{2} \\
& v=\frac{\left(v_{i}^{1}+v_{j}^{1}\right)}{2 \times C}
\end{aligned}
$$

where: 


$$
C= \begin{cases}\sum_{j=1}^{m} \sum_{i=1}^{n}\left(\frac{v_{i}^{1}+v_{j}^{2}}{2}\right) & \sum_{i=1}^{n} v_{i}^{1}=1 \text { and } \sum_{j=1}^{n} v_{j}^{2}=1 ; \\ \sum_{j=1}^{m} \sum_{i=1}^{n}\left(\frac{v_{i}^{1}+v_{j}^{2}}{2}\right)+\sum_{j=1}^{m}\left(\frac{v_{c}^{1}+v_{j}^{2}}{2}\right) & \sum_{i=1}^{n} v_{i}^{1}<1 \text { and } \sum_{j=1}^{n} v_{j}^{2}=1 ; \\ \sum_{j=1}^{m} \sum_{i=1}^{n}\left(\frac{v_{i}^{1}+v_{j}^{2}}{2}\right)+\sum_{i=1}^{n}\left(\frac{v_{i}^{1}+v_{c}^{2}}{2}\right) & \sum_{i=1}^{n} v_{i}^{1}=1 \text { and } \sum_{j=1}^{n} v_{j}^{2}<1 ; \\ \sum_{j=1}^{m} \sum_{i=1}^{n}\left(\frac{v_{i}^{1}+v_{j}^{2}}{2}\right)+\sum_{j=1}^{m}\left(\frac{v_{c}^{1}+v_{j}^{2}}{2}\right)+\sum_{i=1}^{n}\left(\frac{v_{i}^{1}+v_{c}^{2}}{2}\right) & \sum_{i=1}^{n} v_{i}^{1}<1 \text { and } \sum_{j=1}^{n} v_{j}^{2}=1 ;\end{cases}
$$

where $v_{c}^{1}=1-\sum_{i=1}^{n} v_{i}^{1}$ and $v_{c}^{2}=1-\sum_{j=1}^{m} v_{j}^{2}$.

\subsection{Interval Numbers Decision Based on Entropy Weight}

According to the basic principle of information theory, information is the orderly degree of a measurement system. The entropy is a measurement of disorder degree in a system. The absolute value of them is equal, while their symbol is inverse. Therefore, many scholars use Entropy weight method to measure the weight. The smaller information entropy is, the higher weight is [8] [9]. Entropy weight method is introduced as below.

Definition 2.7. For MADM, any solution set $X=\left(x_{1}, x_{2}, \cdots, x_{n}\right), U=\left(u_{1}, u_{2}, \cdots, u_{n}\right)$ is a property set. Information entropy is defined as:

$$
E=-\frac{1}{\ln n} \sum_{i=1}^{n} x_{i} \ln x_{i}
$$

Using the formula (2) (3) (4), we have the standardized matrix $R=\left(r_{i j}\right)$. The matrix $R=\left(r_{i j}\right)$ is normalized as $\stackrel{*}{R}=\left(r_{i j}^{*}\right)$, where

$$
{\stackrel{*}{r_{i j}}}^{*}=\frac{r_{i j}}{\sum_{i=1}^{n} r_{i j}}
$$

Then, attribute $u_{j}$ has information entropy

$$
E_{j}=-\frac{1}{\ln n} \sum_{i=1}^{n} r_{i j}^{*} \ln r_{i j}^{*}
$$

Specially, we have: $r_{i j}^{*} \ln r_{i j}^{*}=0$ when $r_{i j}^{*}=0$.

According to information entropy, the attribute's weight vector can be calculated as follows,

$$
\omega=\left(\omega_{1}, \omega_{2}, \cdots, \omega_{n}\right)
$$

with

$$
\omega_{j}=\frac{1-E_{j}}{\sum_{k=1}^{m}\left(1-E_{k}\right)}
$$


The comprehensive attribute values can be obtained as below,

$$
z_{i}=\sum_{j=1}^{m} \omega_{j} r_{i j}
$$

According to the value of $z_{i}$, the rank of investment decision is given. Finally, the MADM problem is solved according to the ranking.

\section{Proposed Method}

\subsection{A New MADA Based on D Numbers Methods}

In this section, a new MADA model for investment project is proposed. In this model, firstly, the uncertain information of investment decision is represented by using interval number and D numbers theory. The uncertain information is given as follows,

$$
A=\left(D_{1}, D_{2}, \cdots, D_{n}\right)^{\mathrm{T}}
$$

where

$$
D=\left(\left[a_{1}^{L_{1}}, a_{1}^{U_{1}}\right], v_{1}\right), \cdots,\left(\left[a_{i}^{L_{i}}, a_{i}^{U_{i}}\right], v_{i}\right)
$$

where $\left[a_{i}^{L_{i}}, a_{i}^{U_{i}}\right]$ is an interval number, $v_{i}$ is real number for the interval number of the uncertainty information. We have: $0<v_{i}<1$ and $\sum_{i} v_{i} \leq 1$. According to Equation (2), the decision matrix of uncertainty factors $A$ is obtained. Secondly, using Equation (6), the corresponding matrix is obtained. Considering type of factors, the corresponding matrix must change into the standard matrix $R$. Thus, the standard matrix $R$ is obtained according to Equations (3), (4) and (11) at third step. Lastly, the weights of uncertainty factors are calculated by using entropy weight method. According to Equation (14), the value of each decision is calculated. So, we make decision according to the value of each decision.

\subsection{A Numerical Example}

In this section, a numerical example is introduced for describing the proposed method. Supposing for promoting a new product, a company plans to choose a project from the four investment projects. These investment projects are denoted as $A_{1}, A_{2}, A_{3}$ and $A_{4}$, respectively. Four attributes are considered in evaluating the four choices, they are amount investment (million dollar) denoted as $u_{1}$, the expected net present value (million dollar) denoted as $u_{2}$, the risk profit value (million dollar) denoted as $u_{3}$ and the risk loss value (million dollar) denoted as $u_{4}$. In uncertainty theory, uncertain factors in many fields is determined by expert assessment measures. Then the company invites ten experts to give the assessments. In many previous studies, $b_{i}$ is a definite value, but in the study of uncertain information, mostly is blurred, so using interval number to represent by $b_{i}$. In $\mathrm{D}$ numbers, the value of $v_{i}$ is depended on the percent of experts who agree with $b_{i}$. For example, for the attribute $u_{1}$ in investment project $A_{1}$, seven experts think that the value of it is $[5.00,5.40]$ and two experts think that is $[5.20,5.50]$. Another one don't give any value. So we have $u_{1}=(([5.00,5.40], 0.7),([5.20,5.50], 0.2))$. 
Similarly, all assessment are given by the combination of interval number and D numbers, which are shown as below,

$$
\left[\begin{array}{llll}
A_{1} & A_{2} & A_{3} & A_{4}
\end{array}\right]
$$

where

$$
\begin{aligned}
& A_{1}=\left[\begin{array}{l}
\{([5.00,5.40], 0.7),([5.20,5.50], 0.2)\} \\
\{([4.80,5.20], 0.7),([5.00,5.60], 0.3)\} \\
\{([4.72,4.74], 0.9),([4.73,4.77], 0.1)\} \\
\{([0.45,0.47], 0.6),([0.44,0.46], 0.4)\}
\end{array}\right] \\
& A_{2}=\left[\begin{array}{c}
\{([10.02,10.10], 0.6),([10.08,10.12], 0.3),([10.10,10.12], 0.1)\} \\
\{([6.50,6.90], 0.8),([6.60,6.70], 0.1)\} \\
\{([5.70,5.74], 0.9),([5.72,5.76], 0.1)\} \\
\{([1.58,1.62], 0.8),([1.59,1.63], 0.1),([1.60,1.64], 0.1)\}
\end{array}\right] \\
& A_{3}=\left[\begin{array}{c}
\{([5.20,5.30], 0.9),([5.30,5.40], 0.1)\} \\
\{([4.00,4.40], 0.8),([4.20,4.40], 0.1),([4.30,4.50], 0.1)\} \\
\{([3.80,3.84], 0.7),([3.84,3.86], 0.2),([3.86,3.88], 0.1)\} \\
\{([0.47,0.49], 0.8),([0.48,0.52], 0.2)\}
\end{array}\right] \\
& A_{4}=\left[\begin{array}{c}
\{([9.60,9.80], 0.7),([9.70,9.90], 0.3)\} \\
\{([5.00,5.40], 0.9),([5.20,5.62], 0.1)\} \\
\{([5.45,5.55], 0.7),([5.50,5.54], 0.1),([5.52,5.58], 0.1)\} \\
\{([1.30,1.40], 0.7),([1.36,1.42], 0.2)\}
\end{array}\right]
\end{aligned}
$$

For calculating the weight of each attribute, the process can be divided into four steps.

Step 1. Using the formula: $a_{i j}=\frac{\left(a^{L}+a^{U}\right)}{2}$, all the assessment are given by D numbers and shown as follows,

$$
\begin{aligned}
& A_{1}^{\prime}=\left[\begin{array}{c}
\{(5.20,0.7),(5.35,0.2)\} \\
\{(5.00,0.7),(5.30,0.3)\} \\
\{(4.73,0.9),(4.75,0.1)\} \\
\{(0.46,0.6),(0.45,0.4)\}
\end{array}\right] \\
& A_{2}^{\prime}=\left[\begin{array}{c}
\{(10.06,0.6),(10.10,0.3),(10.11,0.1)\} \\
\{(6.70,0.8),(6.65,0.1)\} \\
\{(5.72,0.9),(5.74,0.1)\} \\
\{(1.60,0.8),(1.61,0.1),(1.62,0.1)\}
\end{array}\right]
\end{aligned}
$$




$$
\begin{gathered}
A_{3}^{\prime}=\left[\begin{array}{c}
\{(5.25,0.9),(5.35,0.1)\} \\
\{(4.20,0.8),(4.30,0.1),(4.40,0.1)\} \\
\{(3.82,0.7),(3.85,0.2),(3.87,0.1)\} \\
\{(0.48,0.8),(0.50,0.2)\}
\end{array}\right] \\
A_{4}^{\prime}=\left[\begin{array}{c}
\{(9.70,0.7),(9.80,0.3)\} \\
\{(5.20,0.9),(5.41,0.1)\} \\
\{(5.50,0.7),(5.52,0.1),(5.55,0.1)\} \\
\{(1.35,0.7),(1.39,0.2)\}
\end{array}\right]
\end{gathered}
$$

Step 2. We replace the $\mathrm{D}$ numbers in the matrix by $I(D)=\sum_{i=1}^{n}\left(b_{i} v_{i}\right)$ the corresponding matrix is obtain as follows,

$$
R=\left(D_{i j}\right)=\left[\begin{array}{cccc}
4.710 & 5.090 & 4.723 & 0.456 \\
10.077 & 6.025 & 5.722 & 1.630 \\
5.260 & 4.230 & 3.831 & 0.484 \\
9.730 & 5.221 & 4.957 & 1.223
\end{array}\right]
$$

Step 3. The expected net present value and risk profit value are the benefit type. Amount of investment and risk loss value are the cost benefit attributes. Using the formula (3) (4) (11), we can get the normalized matrix $\stackrel{*}{R}=\left(r_{i j}^{*}\right)$

$$
\stackrel{*}{R}=\left(r_{i j}^{*}\right)=\left[\begin{array}{cccc}
0.351 & 0.247 & 0.246 & 0.386 \\
0.164 & 0.293 & 0.297 & 0.108 \\
0.315 & 0.206 & 0.199 & 0.364 \\
0.170 & 0.254 & 0.258 & 0.143
\end{array}\right]
$$

Step 4. Using the formula (12) obtains the output information entropy of attribute $u_{j} \cdot$

$$
E=(0.959,0.994,0.993,0.904)
$$

According to Equation (13), the attribute's weight vector can be calculated as follows,

$$
\omega_{1}=0.275, \omega_{2}=0.037, \omega_{3}=0.048, \omega_{4}=0.640
$$

Using Equation (14), each value of scheme $x_{j}$ can be obtained as follows,

$$
z_{1}=2.003, \quad z_{2}=4.312, \quad z_{3}=2.097, \quad z_{4}=3.896
$$

So, we have $z_{2}>z_{4}>z_{3}>z_{1}$. The rank of investment projects is $x_{2}>x_{4}>x_{3}>x_{1}$. Thus, the second investment project is the best choice in four plans for company. In our methods, every uncertainty factor is represented by interval number. Furthermore, incomplete information is revealed D numbers method. For compare with previous methods, our proposed method is more flexible. It is accord with the actual circumstance in investment decision. 


\section{Conclusion}

Although there are many methods to deal with investment decision problems, no method represents the uncertainty and incomplete information in investment project. In this paper, the combination of interval number and D numbers method is used to deal with investment decision problems. All the assessments are represented by the combination of interval number and $\mathrm{D}$ numbers. Meanwhile, the weights of uncertainty factors are calculated using entropy weight method. Thus, a new MADM model for investment decision is proposed. A numerical example is used to illustrate the efficiency of the proposed method.

\section{Acknowledgements}

The work is partially supported by Found of Educational Commission of Hubei Province of China (Grant No. D20151902), the Doctoral Scientific Research Foundation of Hubei University for Nationalities (Grant No. my2014b003), the Training Programs of Innovation and Entrepreneurship for Undergraduates of Hubei University for Nationalities (Grant No. 2014Z046).

\section{References}

[1] Hirshleifer, J. (1965) Investment Decision under Uncertainty: Choice-Theoretic Approaches. Quarterly Journal of Economics, 79, 509-536. http://dx.doi.org/10.2307/1880650

[2] Deng, G.F. and Lin, W.T. (2010) Ant Colony Optimization for Markowitz Mean Variance Portfolio Model. Springer, Berlin Heidelberg. http://dx.doi.org/10.1007/978-3-642-17563-3 29

[3] Meyer, J.R. and Kuh, E. (1957) The Investment Decision: An Empirical Study. Harvard University Press, Harvard.

[4] Farrar, D.E. (1962) The Investment Decision under Uncertainty. Prentice-Hall, Englewood Cliffs, 379-394.

[5] Rubinstein, M. (2002) Markowitzs Portfolio Selection: A Fifty-Year Retrospective. The Journal of Finance, 57, 1041-1045. http://dx.doi.org/10.1111/1540-6261.00453

[6] Goldstein, I. and Razin, A. (2006) An Information-Based Trade-Off between Foreign Direct Investment and Foreign Portfolio Investment. Journal of International Economics, 70, 271-295. http://dx.doi.org/10.1016/j.jinteco.2005.12.002

[7] Bollerslev, T., Engle, R.F. and Wooldridge, J.M. (1988) A Capital Asset Pricing Model with Time-Varying Covariances. The Journal of Political Economy, 96, 116-131. http://dx.doi.org/10.1086/261527

[8] Xue, Y. and Boulton, W.R. (2008) Information Technology Governance in Information Technology Investment Decision Processes: The Impact of Investment Characteristics, External Environment, and Internal Context. MIS Quarterly, 32, 67-96.

[9] Huberman, G., Wang, Z., et al. (2005) Arbitrage Pricing Theory. Technical Report, Federal Reserve Bank of New York.

[10] Levy, H. (2006) Stochastic Dominance: Investment Decision Making under Uncertainty. Springer, Berlin, 757-776.

[11] Todea, A. and Plesoianu, A. (2013) The Influence of Foreign Portfolio Investment on Informational Efficiency: Empirical Evidence from Central and Eastern European Stock 
Markets. Economic Modelling, 33, 34-41. http://dx.doi.org/10.1016/j.econmod.2013.03.017

[12] Beliakov, G. (2003) How to Build Aggregation Operators from Data. International Journal of Intelligent Systems, 18, 903-923. http://dx.doi.org/10.1002/int.10120

[13] Wei, D., Deng, Y. and Li, Y. (2012) Multi-Criteria Safety Evaluation Index with Topsis under Uncertain Environment. ICIC Express Letters, Part B: Applications, 3, 83-89.

[14] Xu, Z. (2015) Uncertain Multi-Attribute Decision Making: Methods and Applications. Springer, Berlin. http://dx.doi.org/10.1007/978-3-662-45640-8

[15] Pei, Z. and Zheng, L. (2012) A Novel Approach to Multi-Attribute Decision Making Based on Intuitionistic Fuzzy Sets. Expert Systems with Applications, 39, 2560-2566. http://dx.doi.org/10.1016/j.eswa.2011.08.108

[16] Huang, X., Wang, N. and Wei, D. (2016) Investment Decision Using D Numbers. Control and Decision Conference, Las Vegas, 12-14 December 2016, 4164-4167. http://dx.doi.org/10.1109/ccdc.2016.7531712

[17] You, T.H. and Gao, M.L. (2012) An Approach to Multiple Attribute Decision Making with Intervals Considering the Risk Preferences of Decision-Makers. Operations Research Management Science.

[18] Deng, X., Lu, X., Chan, F.T.S., Sadiq, R., Mahadevan, S. and Deng, Y. (2015) D-CFPR: D Numbers Extended Consistent Fuzzy Preference Relations. Knowledge-Based Systems, 73, 61-68. http://dx.doi.org/10.1016/j.knosys.2014.09.007

[19] Gao, F.J. (2000) Multiple Attribute Decision Making on Plans with Alternative Preference under Incomplete Information. Systems Engineering Theory Practice.

[20] Deng, X., Hu, Y., Deng, Y. and Mahadevan, S. (2014) Supplier Selection Using AHP Methodology Extended by D Numbers. Expert Systems with Applications, 41, 156-167. http://dx.doi.org/10.1016/j.eswa.2013.07.018

[21] Dai, J., Wang, W. and Mi, J.-S. (2013) Uncertainty Measurement for Interval-Valued Information Systems. Information Sciences, 251, 63-78. http://dx.doi.org/10.1016/j.ins.2013.06.047

[22] Verma, A.K., Ajit, S. and Karanki, D.R. (2016) Uncertainty Analysis in Reliability/Safety Assessment. In: Verma, A.K., Ajit, S. and Karanki, D.R., Eds., Reliability and Safety Engineering, Springer, Berlin, 457-491. http://dx.doi.org/10.1007/978-1-4471-6269-8 13

[23] Tong, S. (1994) Interval Number and Fuzzy Number Linear Programmings. Fuzzy Sets and Systems, 66, 301-306. http://dx.doi.org/10.1016/0165-0114(94)90097-3

[24] Fu, Y., Jiang, H., Xiao, N., Tian, L., Liu, F. and Xu, L. (2014) Application-Awarelocal-Global Source Deduplication for Cloud Backup Services of Personal Storage. IEEE Transactions on Parallel and Distributed Systems, 25, 1155-1165. http://dx.doi.org/10.1109/TPDS.2013.167

[25] Wei, D., Deng, X., Zhang, X., Deng, Y. and Mahadevan, S. (2013) Identifying Influential Nodes in Weighted Networks Based on Evidence Theory. Physica A: Statistical Mechanics \& Its Applications, 392, 2564-2575. http://dx.doi.org/10.1016/j.physa.2013.01.054

[26] Yager, R.R. and Alajlan, N. (2013) Decision Making with Ordinal Payoffs under DempsterShafer Type Uncertainty. International Journal of Intelligent Systems, 28, 1039-1053. http://dx.doi.org/10.1002/int.21615

[27] Yu, C., Yang, J., Yang, D., Ma, X. and Min, H. (2015) An Improved Conflicting Evidence Combination Approach Based on a New Supporting Probability Distance. Expert Systems with Applications, 42, 5139-5149. http://dx.doi.org/10.1016/j.eswa.2015.02.038

[28] Tang, H. (2015) A Novel Fuzzy Soft Set Approach in Decision Making Based on Grey Relational Analysis and Dempster-Shafer Theory of Evidence. Applied Soft Computing, 31, 
317-325. http://dx.doi.org/10.1016/j.asoc.2015.03.015

[29] Deng, Y., Mahadevan, S. and Zhou, D. (2015) Vulnerability Assessment of Physical Protection Systems: A Bio-Inspired Approach. International Journal of Unconventional Computing, 11, 227-243.

[30] Jiang, W., Wei, B., Xie, C. and Zhou, D. (2016) An Evidential Sensor Fusion Method in Fault Diagnosis. Advances in Mechanical Engineering, 8, 1-7.

http://dx.doi.org/10.1177/1687814016641820

[31] Deng, Y. (2012) D Numbers: Theory and Applications. Journal of Information and Computational Science, 9, 2421-2428.

[32] Weisberg, J. (2010) Dempster-Shafer Theory. University of Toronto, Toronto.

[33] Deng, X., Hu, Y., Deng, Y. and Mahadevan, S. (2014) Environmental Impact Assessment Based on D Numbers. Expert Systems with Applications, 41, 635-643.

http://dx.doi.org/10.1016/j.eswa.2013.07.088

[34] Liu, H.C., You, J.X., Fan, X.J. and Lin, Q.L. (2014) Failure Mode and Effects Analysis Using D Numbers and Grey Relational Projection Method. Expert Systems with Applications, 41, 4670-4679. http://dx.doi.org/10.1016/j.eswa.2014.01.031

[35] Deng, X., Hu, Y. and Deng, Y. (2014) Bridge Condition Assessment Using D Numbers. Scientific World Journal, 2014, 358057-358057. http://dx.doi.org/10.1155/2014/358057

[36] Fan, G., Zhong, D., Yan, F. and Yue, P. (2016) A Hybrid Fuzzy Evaluation Method for Curtain Grouting Efficiency Assessment Based on an AHP Method Extended by D Numbers. Expert Systems with Applications, 44, 289-303.

http://dx.doi.org/10.1016/j.eswa.2015.09.006

[37] Lai, K.K., Wang, S.Y., Xu, J.P., Zhu, S.S. and Fang, Y. (2003) A Class of Linear Interval Programming Problems and Its Application to Portfolio Selection. IEEE Transactions on Fuzzy Systems, 10, 698-704. http://dx.doi.org/10.1109/TFUZZ.2002.805902

[38] Ida, M. (2004) Solutions for the Portfolio Selection Problem with Interval and Fuzzy Coefficients. Reliable Computing, 10, 389-400.

http://dx.doi.org/10.1023/B:REOM.0000032120.83979.d4 
Submit or recommend next manuscript to SCIRP and we will provide best service for you:

Accepting pre-submission inquiries through Email, Facebook, LinkedIn, Twitter, etc.

A wide selection of journals (inclusive of 9 subjects, more than 200 journals)

Providing 24-hour high-quality service

User-friendly online submission system

Fair and swift peer-review system

Efficient typesetting and proofreading procedure

Display of the result of downloads and visits, as well as the number of cited articles

Maximum dissemination of your research work

Submit your manuscript at: http://papersubmission.scirp.org/

Or contact apm@scirp.org 